\title{
Intake of micronutrients high in animal-source foods is associated with better growth in rural Kenyan school children
}

\author{
Monika Grillenberger ${ }^{1 *}$, Charlotte G. Neumann ${ }^{2}$, Suzanne P. Murphy ${ }^{3}$, Nimrod O. Bwibo ${ }^{4}$, \\ Robert E. Weiss ${ }^{5}$, Luohua Jiang ${ }^{5}$, Joseph G. A. J. Hautvast ${ }^{1}$ and Clive E. West $\dagger$ \\ ${ }^{1}$ Division of Human Nutrition, Wageningen University, PO Box 8129, 6700 EV Wageningen, The Netherlands \\ ${ }^{2}$ School of Public Health, University of California, Los Angeles, CA 90095, USA \\ ${ }^{3}$ Cancer Research Center, University of Hawaii at Manoa, Honolulu, HI 96813, USA \\ ${ }^{4}$ School of Medicine, University of Nairobi, Nairobi, Kenya \\ ${ }^{5}$ Department of Biostatistics, School of Public Health, University of California, Los Angeles, CA 90095, USA
}

(Received 22 April 2004 - Revised 25 May 2005 - Accepted 1 July 2005)

\begin{abstract}
Observational studies have shown that children in developing countries consuming diets containing high amounts of bioavailable nutrients, such as those found in animal-source foods, grow better. The present study investigated which specific nutrients from the diet of Kenyan school children predicted their growth. The children ( $n 544$, median age 7 years) participated in a 2-year long food supplementation study with animal-source foods. Height gain during the intervention period was positively predicted by average daily intakes of energy from animalsource foods, haem $\mathrm{Fe}$, preformed vitamin $\mathrm{A}, \mathrm{Ca}$ and vitamin $\mathrm{B}_{12}$. Weight gain was positively predicted by average daily intakes of energy from animal-source foods, haem $\mathrm{Fe}$, preformed vitamin $\mathrm{A}, \mathrm{Ca}$ and vitamin $\mathrm{B}_{12}$. Gain in mid-upper-arm muscle area was positively predicted by average daily intakes of energy from animal-source foods and vitamin $\mathrm{B}_{12}$. Gain in mid-upper-arm fat area was positively predicted by average daily intakes of energy from animal-source foods. Gain in subscapular skinfold thickness was not predicted by any of the nutrient intakes. Negative predictors of growth were total energy and nutrients that are contained in high amounts in plant foods. The study shows that growth was positively predicted by energy and nutrients that are provided in high amounts and in a bioavailable form in meat and milk, and their inclusion into the diets of children in developing countries should be part of all food-based programmes in order to improve micronutrient status and growth.
\end{abstract}

Growth: Nutrient intake: Kenya: Animal-source foods

Growth retardation is still one of the major constraints to full development among children in developing countries and is associated with an increased risk of morbidity and mortality, delayed motor and mental development, and reduced physical capacity (ACC/SCN, 2000). In Kenya, about one-third of children are stunted and $6 \%$ are wasted (Government of Kenya/ UNICEF, 1998). Nutrition and health in the first 2 to 3 years of life can affect the growth and development of children, and most growth faltering occurs during this time. However, the growth of older children is also important for their normal development and some studies have shown that catch-up growth is possible in school-aged children and even in adolescents if factors contributing to impaired growth are eliminated (Graham \& Adrianzen, 1972; Tanner, 1981; Kulin et al. 1982; Proos et al. 1991).

Multiple micronutrient deficiencies - particularly of Fe, I, Zn and vitamin A - are a widespread public health problem in Kenya (Government of Kenya/UNICEF, 1998). Studies in Embu District in the 1980s showed the intake of animalsource foods to be low, with only $1 \%$ of the energy intakes of school children coming from milk and less than $1 \%$ from meat (Calloway et al. 1992). Intakes of $\mathrm{Fe}, \mathrm{Zn}, \mathrm{Ca}$ and vitamins $\mathrm{B}_{12}$ and $\mathrm{E}$ were low in toddlers and school children (Murphy et al. 1995).

Intakes of energy, macronutrients and micronutrients determine in part how well individuals approach their genetic potential for growth (Graham et al. 1981). Deficiencies of energy and protein have long been known to impair linear growth (Garn et al. 1964; Adams \& Berridge, 1969). Micronutrient deficiencies that can impair growth are those of $\mathrm{Zn}$ (Black, 1998), Fe (Judisch et al. 1966; Rao et al. 1980; Bouglé et al. 2000), vitamin A (Santos et al. 1983; Mele et al. 1991; Tarwotjo et al. 1992), Ca and P (Chusilp et al. 1992; Prentice \& Bates, 1994; Black et al. 2002), Cu (Castillo-Duran \& Uauy, 1988), I, Mg, K and Mn (Clausen \& Dorup, 1998). Results of studies providing micronutrient supplements in order to improve growth have been inconclusive and the paucity of studies providing micronutrients through food supplements makes an evaluation of their effect on growth difficult. However, some observational studies have

\footnotetext{
*Corresponding author: Monika Grillenberger, fax +31 317 483342, email Monika.Grillenberger@wur.nl

$\dagger$ Deceased, formerly at Department of Gastroenterology and Hepatology, University Medical Centre Nijmegen, Nijmegen, The Netherlands.
} 
shown that the consumption of animal-source foods is associated with improved nutritional status and growth among children (Graham et al. 1981; Walker et al. 1990; Allen et al. 1992; Paik et al. 1992; Marquis et al. 1997; Uauy et al. 2000).

We carried out a 2-year-long controlled feeding intervention trial to assess growth, morbidity and cognitive outcomes by supplementing rural Kenyan school children with animalsource foods, i.e. meat and milk (Neumann et al. 2003). Specific effects of the food supplementation on growth, cognition and micronutrient status are reported elsewhere (Grillenberger et al. 2003; Siekmann et al. 2003; Whaley et al. 2003). Home food intake changed differently for the four supplementation groups during the intervention period (Murphy et al. 2003), which makes interpretation of the effects of the food supplements on growth more complex. To determine which specific nutrients in the diet from all sources, i.e. home intake and food supplement, predicted interindividual variation in growth of the children, we examined the relationships between the intakes of energy and nutrients with growth. Particular attention was paid to those nutrients known to be associated with growth.

\section{Materials and methods}

\section{Study design}

The study was conducted in Kyeni South Division of Embu District in Eastern Province, Kenya. The study area is rural, with farming as the primary occupation. Staple crops, cultivated in subsistence farming, are maize and beans. Cash crops, which are produced in the area on a small scale, include coffee, cotton and tobacco.

All children ( $n$ 554) enrolled in class 1 (median age 7.4 years) from twelve selected primary schools participated in the study. The schools were randomized to one of four feeding groups:

1. Control: no food supplement provided;

2. Energy supplement: a food supplement based on a local dish of maize, beans and vegetables (githeri);

3. Milk supplement: githeri plus a glass of milk $(200 \mathrm{ml})$; and

4. Meat supplement: githeri cooked with $60 \mathrm{~g}$ of minced beef.

The food supplements were approximately isoenergetic and contained an estimated energy content of $\sim 1050 \mathrm{~kJ}$ $(250 \mathrm{kcal})$ per serving during the first school term of the intervention (from September to November 1998). The energy content of all three food supplements was then increased to $\sim 1255 \mathrm{~kJ}(300 \mathrm{kcal})$ per serving, by increasing the portion size of the energy supplement (from 185 to $230 \mathrm{~g}$ per child), the milk content of the milk supplement (to $250 \mathrm{ml}$ ) and the beef content of the meat supplement (to $85 \mathrm{~g}$ ). The intervention period was 24 months, starting in August 1998 and ending in July 2000. Schools were in session for 3 months, followed by a 1-month holiday. The food supplements were provided during the six school terms on all school days, but not on weekends or school holidays. Details of the study design have been published elsewhere (Neumann et al. 2003).
Ethical approval for the research study was obtained from the Human Subject Protection Committee of the University of California, Los Angeles; the Ethics Committee of the University of Nairobi, School of Medicine, Kenya; and the Office of the President, Government of Kenya. All local and district authorities were involved in the implementation of the study, and the community was extensively informed about the aim and procedures of the intervention. Informed verbal consent of the parents of the study children was obtained before the study.

After completion of the study, the households in the control group were each given a local milk goat. This was chosen by the parents through representative committees as compensation for the food their children missed during the course of the study.

\section{Data collection}

Twelve local women, who had worked as enumerators in the 'Nutrition Collaborative Research Support Program on Food Intake and Human Function' (NCRSP) in the same location in 1984, were retrained to perform the anthropometric data collection. A supervisor monitored the interviews/measurements, checked the forms, and maintained and calibrated the equipment. The area of the twelve schools was divided into three clusters to facilitate data collection and supervision. The enumerators were rotated between clusters and schools to prevent bias. The methods used were based on the NCRSP study. The ages of the children were derived from the census questionnaires or from the school register.

\section{Anthropometry}

Weight, mid-upper-arm circumference, triceps skinfold thickness and subscapular skinfold thickness were measured every month in the first year and every other month in the second year. Height was measured every 4 months in the first year and every 8 months in the second year. In total, 24 months of anthropometric measurements were taken, whereby the measurements of the month preceding the intervention period served as baseline measurements. Measurements of triceps skinfold thickness and mid-upper-arm circumference were used to derive estimates of mid-upper-arm muscle area and mid-upper-arm fat area (Frisancho, 1981), indicators of body muscle and subcutaneous fat mass (Gibson, 1990). Subscapular skinfold thickness was used as an estimate of subcutaneous fat mass on the trunk. Details of the anthropometric measurements have been described earlier (Grillenberger et al. 2003). The height of the mother was measured to the nearest $0.1 \mathrm{~cm}$ once during the study with a light portable wooden device with a footplate, a measuring tape and a headboard.

\section{Food intake}

A $24 \mathrm{~h}$ recall method reported by the child's mother was used to estimate the average daily home intake of energy, nutrients, dietary fibre and phytate for each study child. All days of the week apart from Fridays and Saturdays (because no food intake data were collected on Saturdays and Sundays) were proportionately included in the survey to account for any day-of-the-week effects on food and/or nutrient intakes. 
Food models and local plastic dishes and utensils were used to estimate the portion sizes. The method of the food intake data collection has been described by Murphy et al. (2003). Mothers were encouraged to maintain the usual home diet for the children in the study.

For the baseline nutrient intake, an average of three home food intake measurements preceding the intervention period was used. Nutrient intake during the intervention period contained an average of nineteen food intake measurements at home to which the actual amount of energy and nutrients from the food supplement consumed on the respective day by the individual child was added. Four of the nineteen measurements were carried out during school holidays where no food supplements were provided and therefore contained only the home food intake.

In the data analyses, we used intakes of nutrients that have been shown in other studies to be related to growth (energy, protein, $\mathrm{Zn}, \mathrm{Fe}$, vitamin $\mathrm{A}, \mathrm{Cu}, \mathrm{Ca}, \mathrm{P}, \mathrm{Mg}, \mathrm{K}, \mathrm{Mn}$ ) and intakes of energy and nutrients that are contained in high amounts in animal-source foods (energy from animal-source foods, preformed vitamin $\mathrm{A}$, vitamin $\mathrm{B}_{12}$, haem $\mathrm{Fe}$ and riboflavin). We included intakes of available $\mathrm{Fe}$ and $\mathrm{Zn}$ in the data analyses instead of total Fe and $\mathrm{Zn}$. The amount of available Fe in the diet of the children was predicted using the algorithm of Hallberg et al. (Hallberg \& Hulthén, 2000), which considers enhancing and inhibiting effects of a number of dietary factors on haem and non-haem Fe absorption if present in the same meal and the Fe status of the children. Haem Fe in the diet was calculated as $40 \%$ of the meat/fish/poultry $\mathrm{Fe}$, with the remainder being non-haem Fe. Calculations of $\mathrm{Zn}$ bioavailability assumed basal requirements (i.e. negligible stores but no functional impairment) and considered phytate as an inhibiting dietary component of $\mathrm{Zn}$ absorption. A $\mathrm{Zn}$ absorption of $35 \%$ was assumed for phytate: $\mathrm{Zn}$ molar ratios of 5-15, a $\mathrm{Zn}$ absorption of $15 \%$ for phytate: $\mathrm{Zn}$ molar ratios of $15-30$ and a $\mathrm{Zn}$ absorption of $10 \%$ for phytate:Zn molar ratios $>30$. Dietary fibre and phytate, which are contained in large amounts in cereals and legumes, were included in the analyses as a proxy for a diet high in plant foods with a low bioavailability of minerals.

\section{Socio-economic status of the families}

A composite score for the socio-economic status (SES) of each family was derived from economic and social variables of the household which were collected at baseline by interview. It included land ownership and area cultivated, number and type of livestock owned, source and amount of income, income from food products, type and income from cash crops, expenditures, household possessions, the construction of the house and the type of fuel used for cooking. Social factors included church and Sunday school attendance, membership in self-help groups or organizations. An index of 'modernity' included use of bank, telephone and/or post office, ownership of National Social Security Fund card, credit from cooperative, a bank account, household adoption of agricultural or other improvements or innovations, and whether household members listened to radio/television and/ or read the newspaper at least once a week. The use of an external kitchen was included as a separate variable in the analyses. Variables were weighted and answers were assigned points respectively, e.g. for the variable land ownership: a household could get up to 9 points (no land, 0 points; $<2$ acres, 2 points; $2-4.9$ acres, 4 points; 5-7.9 acres, 6 points; $8-11$ acres, 8 points; $>11$ acres, 9 points). These points were added up to a total SES score, whereby a higher score represents a higher level of SES.

\section{Data analysis}

All forms were checked by the supervisors in the field to allow immediate revisits for gross errors or missing data. Forms were collected twice a week from the field offices and they were checked and cleaned. The forms were then entered by scanning using TELEform (Cardiff Software, Vista, CA, USA) or they were entered manually in an Access database (Microsoft, Redmond, WA, USA). The data then were printed and checked for errors against the forms and range-checked by computer.

Longitudinal data models were fit with the SAS mixed procedure (SAS Version 8; SAS Institute, Cary, NC, USA). It was assumed that each subject's data followed a subject-specific line over time with a subject-specific random intercept and random slope. For covariates, sex, baseline age and SES were considered. Additionally, time squared and interactions of SES with time and sex with time were included. Models were adjusted for treatment, i.e. food supplements provided, by including treatment and treatment by time interaction. For each nutrient considered, we included nutrient intake and the nutrient intake by time interaction in the model. Nutrient intake was adjusted for total energy intake in order to evaluate dietary quality and not only dietary quantity. Fixed and random components entered the mixed linear regression models as variables with corresponding parameters in the form:

$$
\begin{aligned}
& Y_{i j}=b_{0}+b_{1} \times \text { time }_{i j} \times \text { time }_{i j}+b_{2} \times \text { age }_{i}+b_{3} \times \operatorname{sex}_{i}+b_{4} \\
& \times \operatorname{sex}_{i} \times \text { time }_{i j}+b_{5} \times \mathrm{SES}_{i}+b_{6} \times \mathrm{SES}_{i} \times \mathrm{time}_{i j}+b_{7} \\
& \times \text { nutrient } \text { intake }_{i}+b_{8} \times \text { nutrient } \text { intake }_{i} \times \text { time }_{i j}+b_{9} \\
& \times \text { energy }_{i}+b_{10} \times \text { energy }_{i} \times \text { time }_{i j}+b_{11} \times \text { treatment }_{i} \\
& +b_{12} \times \text { treatment }_{i} \times \text { time }_{i j}+u_{0 i}+u_{1 i} \times \text { time }_{i j}+e_{i j},
\end{aligned}
$$

where $i=1, \ldots, n ; j=1, \ldots, n_{i}$ (total number of visits for the $i$ th child); $Y$ is the anthropometric response variable, $b_{0}$ is the overall intercept (fixed effect); $u_{0 i}$ is the random intercept; $u_{1 i}$ is the random slope; and $e_{i j}$ is the random noise. School effect was tested by comparing the above-described models including and excluding a school variable. Models were tested with and without the inclusion of mother's height, but due to a high number of missing values, it was not included in final models in order to avoid reduced sample size and power.

Of the explaining variables, sex was coded as dummy (0/1); the other variables were entered as continuous variables. Models were fit for baseline nutrient intakes as predictors and baseline and intervention period anthropometric variables as responses, and for intervention period nutrient intakes as predictors and intervention period anthropometric variables as responses. A positive coefficient of the intervention period nutrient intake by time interaction indicates that higher levels of nutrient intake lead to increased growth rates over time. 
The slope estimates for a child at the 10th and 90th percentile daily intake levels over a period of 12 months were used to calculate effect sizes:

Effect size (90th percentile daily intake $v$. 10th percentile intake)

of nutrient $\mathrm{X}$ over 12 months $=$ slope estimate

(nutrient intake $\times$ time $) \times 90$ th percentile daily intake of

nutrient $\mathrm{X} \times 30$ days $\times 12-$ slopeestimate

(nutrient intake $\times$ time $) \times 10$ th percentile daily intake

of nutrient $\mathrm{X} \times 30$ days $\times 12$.

Differences were reported along with the significance level of the nutrient intake by time interaction.

Differences in growth for the different nutrient intakes between boys and girls and stunted (baseline height-for-age $\mathrm{Z}$-score $<-2$ ) and non-stunted (baseline height-for-age $\mathrm{Z}$-score $\geq-2$ ) children were checked by including an interaction term of nutrient intake by time by sex and an interaction of nutrient intake by time by stunting $(0 / 1$ coded $)$ in the models.

\section{Results}

Of the 554 children eligible for the study, anthropometric data could not be collected for children who left before the feeding intervention started $(n 7)$, were handicapped $(n 14)$, were siblings ( $n 33)$ and for households that were not cooperative (n 2), leaving 498 children for data analysis (257 boys; 241 girls). Complete data for height (seven measurements) were available for $84 \%$ and for weight, skinfold thicknesses and mid-upper-arm circumference (sixteen measurements) for $76 \%$ of the children.

Means and standard deviations of baseline age, SES and anthropometric variables and growth during the intervention period are presented in Table 1 overall and by sex. At baseline, boys in the study were significantly older, weighed more and were taller than girls, but had a higher prevalence of stunting and severe stunting at baseline. Boys had a higher mid-upper-arm muscle area and lower subscapular skinfold thickness and mid-upper-arm fat area than girls. During the intervention period, girls gained more height and mid-upper-arm fat area than boys, but only boys improved their height-for-age $\mathrm{Z}$-score. At the end of the intervention period, twelve $(2.8 \%)$ children who were non-stunted at baseline were stunted, six $(1.4 \%)$ children became severely stunted, one child who was severely stunted became stunted and nineteen children $(4.4 \%)$ became non-stunted. Two $(0.5 \%)$ children became non-wasted, whereas eleven $(2.8 \%)$ children became wasted. Values for the SES score ranged from 20 to 248 with a median of 83 .

In Table 2 mean energy and nutrient intakes during the intervention period are shown. Intake of total energy might have been adequate compared with the mean required energy intakes of $6700 \mathrm{~kJ} / \mathrm{d}(\sim 1600 \mathrm{kcal} / \mathrm{d})$ for children of this age and weight (Torun et al. 1996). However, it is difficult to evaluate true adequacy without knowing activity levels. Additional energy might also be needed for catch-up growth in the stunted children (Allen, 1994) and furthermore, the

Table 1. Summary of baseline age and anthropometric variables and growth during intervention period $\dagger$ (Values are means and standard deviations or $n(\%)$ )

\begin{tabular}{|c|c|c|c|c|c|c|c|c|}
\hline & \multirow[b]{2}{*}{$n$} & \multicolumn{2}{|c|}{ All children } & \multicolumn{2}{|c|}{ Boys } & \multicolumn{2}{|c|}{ Girls } & \multirow[b]{2}{*}{$P \ddagger$} \\
\hline & & Mean & SD & Mean & SD & Mean & SD & \\
\hline \multicolumn{9}{|l|}{ Baseline§ } \\
\hline Age (months) & 496 & $89 \cdot 0$ & $15 \cdot 2$ & $91 \cdot 0$ & $15 \cdot 9$ & $86 \cdot 9$ & $14 \cdot 2$ & 0.003 \\
\hline SES score & 494 & $90 \cdot 0$ & $39 \cdot 0$ & 88.5 & $39 \cdot 8$ & 91.5 & 38.2 & 0.394 \\
\hline Height (cm) & 484 & $115 \cdot 6$ & $6 \cdot 1$ & $116 \cdot 3$ & $6 \cdot 1$ & $114 \cdot 7$ & 5.9 & 0.003 \\
\hline Weight (kg) & 483 & $19 \cdot 8$ & $2 \cdot 6$ & $20 \cdot 2$ & $2 \cdot 5$ & $19 \cdot 2$ & $2 \cdot 6$ & $<0.0001$ \\
\hline WHZ & 472 & -0.3 & 0.7 & -0.3 & 0.8 & -0.3 & 0.7 & 0.961 \\
\hline Wasted $(\mathrm{WHZ}<-2)$ & 472 & \multicolumn{2}{|c|}{$3(0.6)$} & \multicolumn{2}{|c|}{$1(0 \cdot 2)$} & \multicolumn{2}{|c|}{$2(0.4)$} & 0.504 \\
\hline $\mathrm{HAZ}$ & 483 & -1.4 & 1.0 & -1.5 & $1 \cdot 1$ & $-1 \cdot 2$ & 0.9 & 0.001 \\
\hline Stunted $(\mathrm{HAZ}<-2)$ & 483 & \multicolumn{2}{|c|}{$122(25 \cdot 3)$} & \multicolumn{2}{|c|}{$74(15 \cdot 3)$} & \multicolumn{2}{|c|}{$48(9.9)$} & 0.026 \\
\hline Severely stunted $(\mathrm{HAZ}<-3)$ & 483 & \multicolumn{2}{|c|}{$22(4.6)$} & \multicolumn{2}{|c|}{$17(3.5)$} & \multicolumn{2}{|c|}{$5(1.0)$} & 0.015 \\
\hline Subscapular skinfold thickness (mm) & 484 & 4.2 & 0.9 & $4 \cdot 0$ & 0.9 & 4.4 & 0.9 & $<0.0001$ \\
\hline Mid-upper-arm muscle area $\left(\mathrm{mm}^{2}\right)$ & 483 & $1562 \cdot 8$ & $207 \cdot 0$ & $1599 \cdot 0$ & $214 \cdot 7$ & $1524 \cdot 0$ & 191.4 & $<0.0001$ \\
\hline Mid-upper-arm fat area $\left(\mathrm{mm}^{2}\right)$ & 483 & $435 \cdot 8$ & $142 \cdot 9$ & $403 \cdot 3$ & $129 \cdot 1$ & $470 \cdot 7$ & $148 \cdot 9$ & $<0.0001$ \\
\hline \multicolumn{9}{|l|}{ Growth during intervention period\| } \\
\hline Height $(\mathrm{cm})$ & 436 & $10 \cdot 16$ & $1 \cdot 8$ & $9 \cdot 85$ & 1.8 & $10 \cdot 51$ & 1.8 & 0.0001 \\
\hline Weight (kg) & 435 & 3.7 & $1 \cdot 3$ & 3.65 & $1 \cdot 2$ & $3 \cdot 84$ & 1.4 & 0.127 \\
\hline WHZ & 391 & -0.2 & 0.5 & $-0 \cdot 1$ & 0.5 & -0.2 & 0.5 & 0.567 \\
\hline $\mathrm{HAZ}$ & 436 & 0.04 & 0.3 & 0.1 & 0.3 & -0.002 & 0.3 & 0.008 \\
\hline Subscapular skinfold thickness (mm) & 436 & -0.5 & 0.8 & -0.4 & 0.8 & -0.5 & 0.7 & 0.063 \\
\hline Mid-upper-arm muscle area $\left(\mathrm{mm}^{2}\right)$ & 435 & $160 \cdot 6$ & $135 \cdot 3$ & $157 \cdot 2$ & $143 \cdot 0$ & $164 \cdot 4$ & $126 \cdot 5$ & 0.579 \\
\hline Mid-upper-arm fat area $\left(\mathrm{mm}^{2}\right)$ & 435 & 37.5 & 114.0 & $18 \cdot 6$ & $106 \cdot 0$ & 58.6 & $119 \cdot 1$ & 0.0002 \\
\hline
\end{tabular}

SES, socio-economic status; WHZ, weight-for-height Z-score; HAZ, height-for-age Z-score.

tIntervention period, period during which the food supplement was provided ( 24 months).

¥ Significance of difference between boys and girls.

$\S$ Measurements in the month preceding the intervention period.

|| Difference between measurements at 24 months and baseline. 
Nutrient intake and growth of Kenyan school children

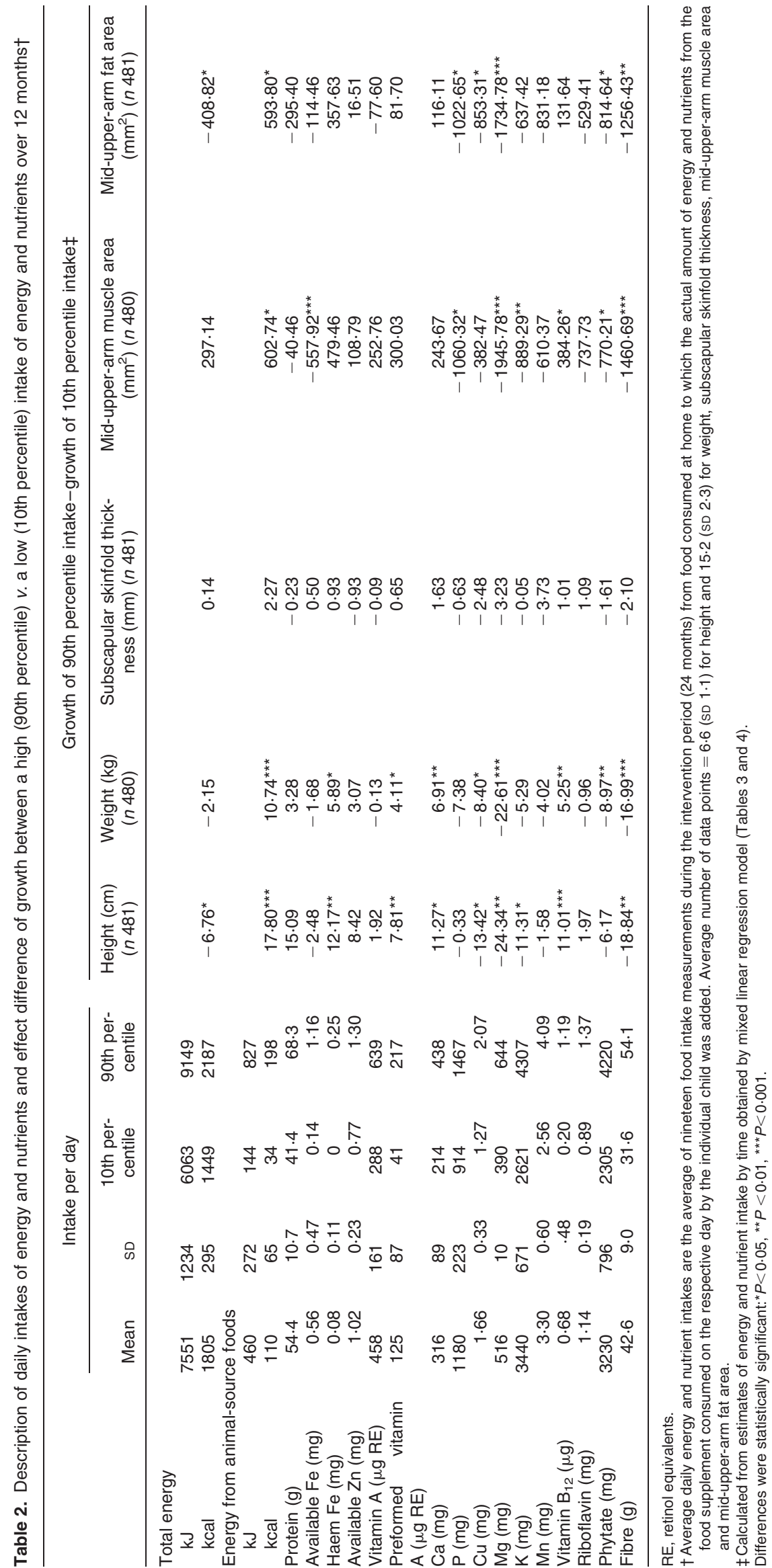


high infection and malaria burden (Siekmann et al. 2003) may contribute to an increased requirement for these children. Recommended protein intakes are $\sim 17 \mathrm{~g} / \mathrm{d}$ (Dewey et al. 1996), whereas actual intakes during the intervention period averaged above $50 \mathrm{~g} / \mathrm{d}$. Prevalences of intakes below estimated average requirements (Institute of Medicine, 1998, 2001a) were $8 \%$ for vitamin A, $69 \%$ for available $\mathrm{Zn}$ and $81 \%$ for vitamin $\mathrm{B}_{12}$. Mean total dietary $\mathrm{Fe}$ intake was 15.3 (SD 3.7) $\mathrm{mg} / \mathrm{d}$, but mean percentage Fe absorption was only $8 \%$ and therefore requirements of absorbed $\mathrm{Fe}$ of $0.8 \mathrm{mg} / \mathrm{d}$ (Institute of Medicine, 2001a) would not have been met by $77 \%$ of the children. Further, it can be assumed that Fe needs are higher in the children due to a high prevalence of infestation with parasites and malaria (Siekmann et al. 2003) that cause blood losses. Average $\mathrm{Ca}$ intakes of $316 \mathrm{mg}$ during the intervention period were much lower than adequate intakes of $800 \mathrm{mg}$ (Institute of Medicine, 2001b).

Average energy and nutrient intakes at baseline, i.e. during the 3 months preceding the food supplementation, were not predictive of baseline anthropometric variables and growth during the intervention period.

Table 3 shows an example of the results of the mixed linear regression models of growth for average daily intake of energy from animal-source foods including all covariates. The estimates of the covariates were similar for the models of the other nutrients and therefore in Table 4 only the estimates for the interaction of average daily nutrient intakes during the intervention period by time (and not the whole model) are presented, whereby a positive significant coefficient indicates that higher levels of nutrient intake lead to increased growth rates over time. Height gain during the intervention period was positively predicted by average daily intakes of energy from animal-source foods, haem Fe, preformed vita$\min \mathrm{A}, \mathrm{Ca}$ and vitamin $\mathrm{B}_{12}$ and negatively predicted by average daily intakes of total energy, $\mathrm{Cu}, \mathrm{Mg}, \mathrm{K}$ and fibre. Weight gain was positively predicted by average daily intakes of energy from animal-source foods, haem $\mathrm{Fe}$, preformed vitamin $\mathrm{A}, \mathrm{Ca}$ and vitamin $\mathrm{B}_{12}$ and negatively predicted by average daily intakes of $\mathrm{Cu}, \mathrm{Mg}$, phytate and fibre. Gain in midupper-arm muscle area was positively predicted by average daily intakes of energy from animal-source foods and vitamin $\mathrm{B}_{12}$ and negatively predicted by average daily intakes of available $\mathrm{Fe}, \mathrm{P}, \mathrm{Mg}, \mathrm{K}$, phytate and fibre. Gain in mid-upper-arm fat area was positively predicted by average daily intakes of energy from animal-source foods and negatively predicted by average daily intakes of total energy, $\mathrm{P}, \mathrm{Cu}, \mathrm{Mg}$, phytate and fibre. Gain in subscapular skinfold thickness was not predicted by any of the nutrient intakes. The inclusion of school as a covariate did not change any of the results (results not shown). If mother's height was included in the models, estimates did not change much. However, $\mathrm{K}$ intake was no longer a significant predictor for height, intakes of energy from animal-source foods, $\mathrm{P}$, vitamin $\mathrm{B}_{12}$ and phytate were no longer significant predictors of mid-upper-arm muscle area, and intake of total energy and $\mathrm{P}$ did not remain as significant predictors for mid-upper-arm fat area. The inclusion of mother's height reduced the sample size by $21 \%$ and was therefore not included in the final models.

To illustrate the effects of energy and nutrients on growth, we calculated differences between a high average daily intake (90th percentile of study children) and a low intake (10th percentile) of energy and nutrients over a period of 12 months (Table 2). For example, if a child consumed every day a diet with a high intake of energy from animal-source foods (90th percentile, $827 \mathrm{~kJ}(198 \mathrm{kcal})$ ), she would gain $18 \mathrm{~cm}$ more in height, $11 \mathrm{~kg}$ more in weight, $2 \mathrm{~mm}$ more subscapular skinfold thickness, $603 \mathrm{~mm}^{2}$ more mid-upper-arm muscle area or $594 \mathrm{~mm}^{2}$ more mid-upper-arm fat area in 12 months compared with a child with a low intake of energy from animal-source foods (10th percentile, $144 \mathrm{~kJ}$ (34 kcal)). In Fig. 1, the effect differences between a high average daily intake (90th percentile of study children) and a low intake (10th percentile) of energy from animal-source foods, preformed vitamin $\mathrm{A}, \mathrm{Ca}$ and vitamin $\mathrm{B}_{12}$ and height gain over 12 months are shown as growth slopes.

Average daily energy and nutrient intakes did not predict any differences in growth between girls and boys. Most of the nutrient intake variables predicted higher growth rates for the stunted than for the non-stunted children for weight, subscapular skinfold thickness, mid-upper-arm muscle area and mid-upper-arm fat area (Table 5). There were no significant differences between stunted and non-stunted children for height.

\section{Discussion}

The setting of the present food supplementation study provided the unique opportunity to compare the growth of Kenyan school children with different diets and therefore varying intakes of energy and nutrients. The usual diet consists predominantly of maize and beans with only $4 \%$ of energy intake from animal-source foods. Energy intake from animal-source foods was increased by $65 \%$ through supplementation with meat and milk. Unlike in many other studies, in addition to energy intake, the intake of multiple nutrients and bioavailability factors, such as fibre and phytate, over a 2-year period were considered in the analyses.

The present study, where the total food intake of the children (i.e. their intake at home plus the intake of the food supplements) was considered and other variables that might have an influence on growth (such as sex, age and SES) were controlled for, shows that growth was positively predicted by energy and nutrients that are provided in high amounts and in a bioavailable form in meat and milk. Height gain was positively predicted by average daily intakes of energy from animal-source foods, haem $\mathrm{Fe}$, preformed vitamin $\mathrm{A}, \mathrm{Ca}$ and vitamin $B_{12}$. Weight gain was positively predicted by average daily intakes of energy from animal-source foods, haem $\mathrm{Fe}$, preformed vitamin $\mathrm{A}, \mathrm{Ca}$ and vitamin $\mathrm{B}_{12}$. These findings indicate that with some animal-source foods added daily to the children's diet, significant differences could be made in improving their height and weight.

In contrast, we did not see this when we earlier compared the growth of the children on the basis of the food supplement they received (Grillenberger et al. 2003). There was no effect of the food supplementation on height gain and the only difference in weight gain was found between the supplemented groups and the control group, indicating that it was not the effect of the meat or milk that was responsible for weight gain, but probably the extra energy intake through the snacks or the intake of vitamin A with which the cooking fat used for all food supplements was fortified. However, there 
Nutrient intake and growth of Kenyan school children

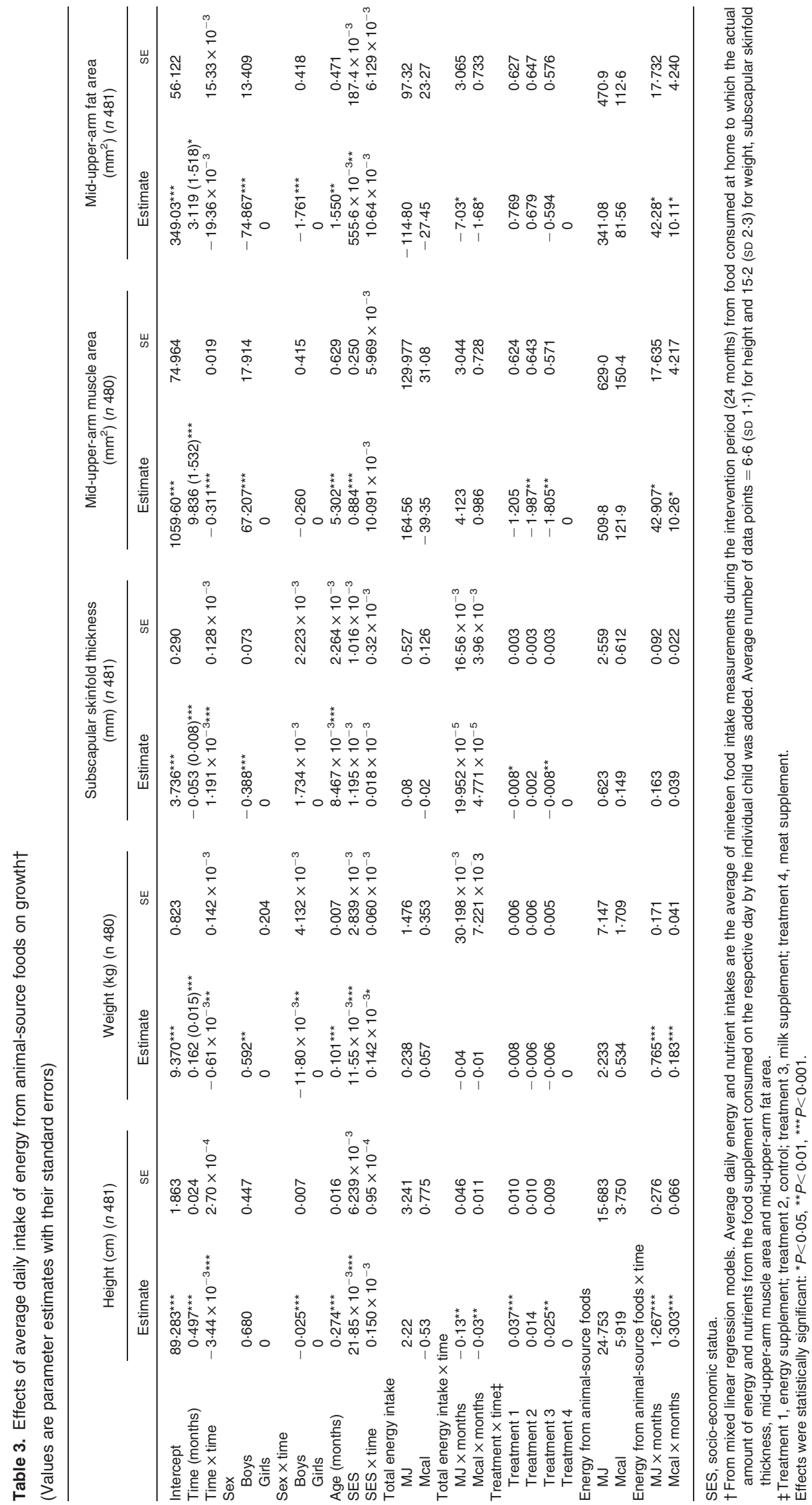


M. Grillenberger et al.

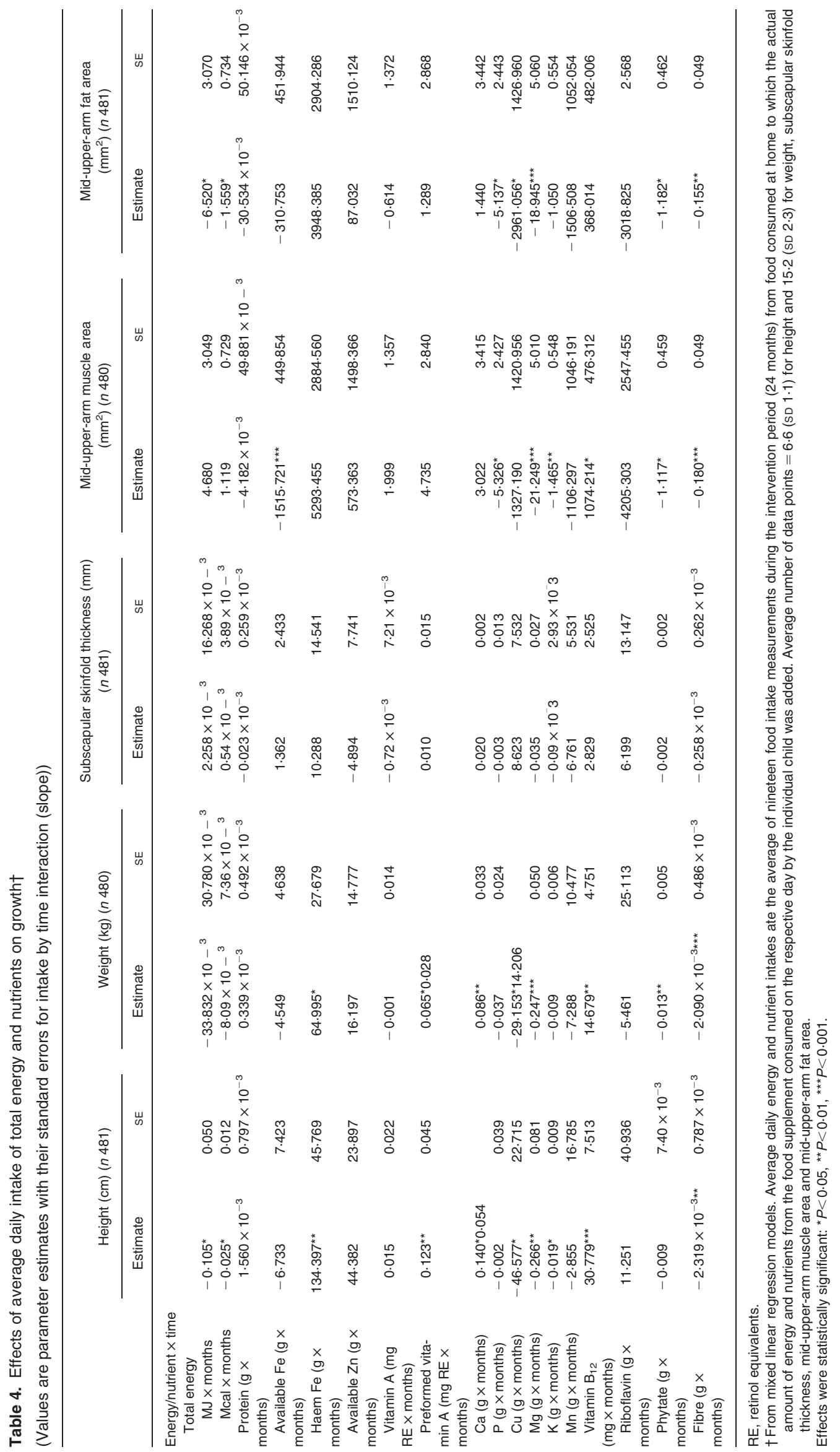



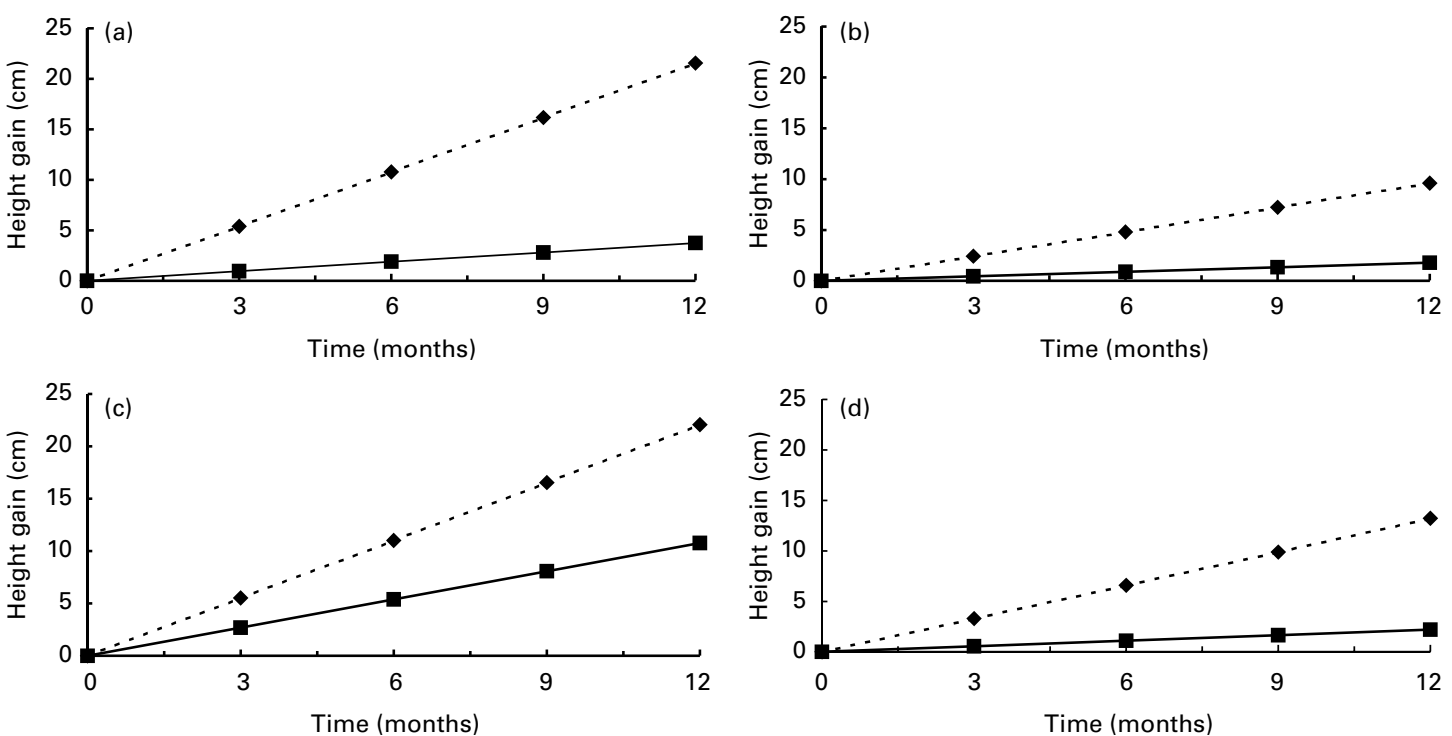

Fig. 1. Effect of intake of energy from animal-source foods (a), preformed vitamin A (b), calcium (c) and vitamin $B_{12}$ (d) over 12 months on height gain among rural Kenyan school children ( $n$ 493) with a low intake (10th percentile; - - ) $v$. a high intake (90th percentile; - - - - ). Average daily energy and nutrient intakes are the average of nineteen food intake measurements during the intervention period ( 24 months) from food consumed at home to which the actual amount of energy and nutrients from the food supplement consumed on the respective day by the individual child was added.

was an unforeseen change in the home diet between baseline and the intervention period, such as that total energy intake of the children in the energy group (only maize and beans with no animal-source foods added) and milk group decreased, whereas it increased in the control (no supplement) and meat groups (Murphy et al. 2003). The current analytical approach might be more sensitive than the previous one as we included total daily intake of energy and nutrients, i.e. the food supplement plus home food intake per child, while controlling for treatment, i.e. the food supplements the children received. However, it has to be taken into consideration that the fat used in preparing the food supplements was enriched with vitamin A (Kimbo, fortified with $124 \mathrm{IU} / \mathrm{g}$; Unilever Kenya Ltd) and therefore the amount of preformed

Table 5. Difference in growth over 12 months between stunted and non-stunted children for average daily intake of energy and nutrients $†$

\begin{tabular}{|c|c|c|c|c|}
\hline & $\begin{array}{l}\text { Weight } \\
\text { (kg) }\end{array}$ & $\begin{array}{l}\text { Subscapular skinfold thickness } \\
\qquad(\mathrm{mm})\end{array}$ & $\begin{array}{l}\text { Mid-upper-arm muscle area } \\
\qquad\left(\mathrm{mm}^{2}\right)\end{array}$ & $\begin{array}{l}\text { Mid-upper-arm fat area } \\
\left(\mathrm{mm}^{2}\right)\end{array}$ \\
\hline \multicolumn{5}{|l|}{ Total energy } \\
\hline MJ & $2 \cdot 51^{\star \star \star}$ & & $54 \cdot 24^{\star *}$ & \\
\hline Mcal & $0 \cdot 6^{\star \star \star}$ & & & \\
\hline \multicolumn{5}{|c|}{ Energy from animal-source foods } \\
\hline MJ & & $6 \cdot 03^{* *}$ & & \\
\hline Mcal & & $1.44^{* *}$ & & \\
\hline Protein $(\mathrm{g})$ & $0.02^{\star \star \star}$ & & $1 \cdot 28^{* \star}$ & \\
\hline Available Zn (mg) & $0.73^{\star *}$ & $0.28^{*}$ & $47.67^{*}$ & \\
\hline Vitamin A (mg RE) & $0.96^{\star *}$ & $0.6^{\star *}$ & $100 \cdot 56^{\star *}$ & $76 \cdot 44^{\star}$ \\
\hline Preformed vitamin A (mg RE) & & $0.96^{*}$ & & \\
\hline $\mathrm{Ca}(\mathrm{g})$ & $1 \cdot 56^{\star}$ & $1.08^{* *}$ & $148 \cdot 56^{*}$ & \\
\hline$P(g)$ & $0.96^{\star \star \star}$ & & $78 \cdot 0^{\star \star}$ & \\
\hline $\mathrm{Cu}(\mathrm{mg})$ & $0.51^{\star \star}$ & & $51 \cdot 96^{\star \star}$ & \\
\hline $\mathrm{Mg}(\mathrm{g})$ & $1.44^{\star \star}$ & & $145 \cdot 92^{\star *}$ & \\
\hline $\mathrm{K}(\mathrm{g})$ & $0 \cdot 24^{\star}$ & & $21 \cdot 12^{\star \star}$ & \\
\hline $\mathrm{Mn}(\mathrm{mg})$ & $0.30^{\star * \star}$ & & $28 \cdot 56^{\star \star}$ & \\
\hline Vitamin $B_{12}(\mu \mathrm{g})$ & & $0 \cdot 19^{* *}$ & & \\
\hline Riboflavin (mg) & $0.92^{* * *}$ & $0.39^{* *}$ & $84 \cdot 87^{\star \star}$ & \\
\hline Phytate (g) & $0 \cdot 24^{\star *}$ & & $20 \cdot 16^{\star \star}$ & \\
\hline Fibre (g) & $0.02^{* *}$ & & $1 \cdot 75^{\star *}$ & \\
\hline
\end{tabular}

RE, retinol equivalents.

† Results are the differences in parameter estimates from the mixed linear regression models for stunted (baseline height-for-age Z-score $<-2$ ) and non-stunted (baseline height-for-age Z-score $\geqq-2$ ) children calculated for 12 months, $n 481$ (stunted, 123; non-stunted, 359). Only significant results are shown, there were no significant differences between stunted and non-stunted children for height. Average daily energy and nutrient intakes are the average of nineteen food intake measurements during the intervention period ( 24 months) from food consumed at home to which the actual amount of energy and nutrients from the food supplement consumed on the respective day by the individual child was added. Differences were statistically significant: ${ }^{\star} P<0.05,{ }^{\star \star} P<0.01,{ }^{\star \star \star} P<0.001$. 
vitamin A was also high in the supplement that did not contain any animal-source foods. Consequently it cannot be assumed that it was only the preformed vitamin A from milk that was beneficial for growth. Intake of total vitamin A, which includes carotenoids, did not have any effect on growth. This finding is in contrast to those of other studies that did not see an association of preformed vitamin A intake and growth, but with intake of dietary carotenoids (Graham et al. 1981; Sedgh et al. 2000). However, it was suggested in the other studies that the lack of association might have been due to limitations in the multivariate analyses as the range of intake of animal-source foods in the study population was small (Sedgh et al. 2000).

Gain in muscle mass was positively predicted by average daily intakes of energy from animal-source foods and vitamin $B_{12}$. This is in agreement with the earlier findings of the study where the growth was compared between the different food supplementation groups (Grillenberger et al. 2003). The children who received meat had greater gains in muscle mass than those in the other groups and also those children who received milk had greater gains in muscle mass than those in the control group (no supplement). Gain in fat mass was positively predicted only by average daily intakes of energy from animalsource foods. This is in contrast to the earlier findings of the study, where we did not find any effect of meat or milk on fat mass.

The findings of the present study indicate that nutrients that are high in plant foods are associated with poorer growth. Negative predictors of height and weight gain were intakes of $\mathrm{Cu}, \mathrm{Mg}$ and fibre; for height gain additionally total energy and $\mathrm{K}$; and for weight gain additionally phytate. This indicates that a diet with no or negligible amounts of animal-source foods and high amounts of starchy foods and legumes rich in inhibitors of bioavailability of minerals, such as phytate and fibre, seem to be disadvantageous for child growth. Gain in mid-upper-arm muscle area was negatively predicted by average daily intakes of available Fe, P, $\mathrm{Mg}, \mathrm{K}$, phytate and fibre.

It is unclear why available Fe would be a negative predictor of muscle mass. However, haem Fe, which is highly bioavailable, was a positive predictor of height and weight gain. It would be expected that increases in the amounts of highly available $\mathrm{Zn}$ and Fe through the meat supplement would be beneficial for growth, especially considering that their bioavailability in the children's habitual diets in the study area is low: $9 \%$ for $\mathrm{Fe}$ and $13 \%$ for $\mathrm{Zn}$ (Murphy et al. 2003). The advantage of the algorithm we used to calculate Fe bioavailability (Hallberg \& Hulthén, 2000) is that it is based on continuous variables for content of enhancers and inhibitors, takes into consideration interactions between factors and includes more factors than previous algorithms. Calculation of $\mathrm{Fe}$ absorption is based on meals, which is expected to give more accurate results than day-based analyses that can e.g. overestimate $\mathrm{Fe}$ absorption if ascorbic acid-rich foods, such as fruits, are consumed between meals, but are considered enhancers of non-haem Fe absorption from other meals. However, accuracy of calculations of Fe bioavailability can only be ensured if contents of dietary factors are known and exact, which is often not the case. We might therefore have over- or underestimated $\mathrm{Fe}$ bioavailability.
Gain in mid-upper-arm fat area was negatively predicted by average daily intakes of total energy, $\mathrm{P}, \mathrm{Cu}, \mathrm{Mg}$, phytate and fibre. These nutrients are mainly contained in the type of diet based on maize and beans with no or only little animal-source foods that the study children habitually consume, which is also low in fat $(\sim 15 \%$ of energy). However, even the increase of fat intake in the children's diets through the food supplementation increased fat mass only little or not at all (Grillenberger et al. 2003).

Children who were stunted at the beginning of the study seem to have benefited more from the intake of total energy and most of the nutrients we examined than the non-stunted children. The nutritional needs of stunted children are higher than those of non-stunted children, and probably their food intake at home is generally lower and other environmental factors are more detrimental than those of the non-stunted children (the reason why they became stunted and probably have a general poorer nutritional status). The earlier findings of the food supplementation study showed that the more stunted children had greater benefits for height gain from the milk supplement than the other children (Grillenberger et al. 2003).

There is some evidence for maternal inheritance of height (Boldsen \& Mascie-Taylor, 1990). However, results with and without mother's height were not much different and, due to a high number of missing values, it was not included in the final models. Height is expected to be influenced not only by genetic but also by environmental factors, and women were found to be short in an earlier study in the same area (Neumann \& Bwibo, 1987). Therefore, at least part of the relationship of mother's height and a child's height is likely to have been reflected in the food intake and SES variables.

The results of the present study show that the intake of nutrients which are contained in large amounts and in an easily available form in meat and milk was beneficial for the growth of the study children who live on a monotonous diet of maize and beans with little other nutritious foods and who suffer from infectious diseases. The promotion of an increased production of animal-source foods and their utilization in the diets of children should be integrated into all food-based programmes to improve the micronutrient status and growth of children in developing countries.

\section{Acknowledgements}

We thank all participants, field and office workers of the Child Nutrition Project in Embu for their contribution to this study. We are grateful to all government officials, headmasters, teachers, doctors, hospital workers and others who facilitated our work.

This work was supported by the Child Nutrition Project of the Global Livestock Collaborative Research Support Program, funded by the Office of Agriculture and Food Security, Global Bureau, United States Agency for International Development, under grant PCE-G-98-00036-00. The opinions expressed do not necessarily reflect the views of the US Agency for International Development. M. G. received financial support from the Netherlands Organization for International Cooperation in Higher Education (NUFFIC), 
The Netherlands and the International Foundation for the Promotion of Nutrition Research and Nutrition Education (ISFE), Switzerland.

\section{References}

Adams P \& Berridge F (1969) Effects of kwashiorkor on cortical and trabecular bone. Arch Dis Child 44, 705-709.

Administrative Committee on Coordination, Sub-Committee on Nutrition of the United Nations (2000) Fourth Report on the World Nutrition Situation. Geneva: ACC/SCN in collaboration with International Food Policy Research Institute.

Allen LH (1994) Nutritional influences on linear growth: a general review. Eur J Clin Nutr 48, Suppl., S75-S89.

Allen LH, Backstrand JR, Stanek EJ 3rd, Pelto GH, Chavez A, Molina E, Castillo JB \& Mata A (1992) The interactive effects of dietary quality on the growth of young Mexican children. Am J Clin Nutr 56, 353-364.

Black MM (1998) Zinc deficiency and child development. Am J Clin Nutr 68, Suppl., S464-S469.

Black R, Williams S, Jones I \& Goulding A (2002) Children who avoid drinking cow milk have low dietary calcium intakes and poor bone health. Am J Clin Nutr 76, 675-680.

Boldsen J \& Mascie-Taylor C (1990) Evidence for maternal inheritance of female height in a British national sample. Hum Biol 62, 767-772.

Bouglé D, Laroche D \& Bureau F (2000) Zinc and iron status and growth in healthy infants. Eur J Clin Nutr 54, 764-767.

Calloway DH, Murphy S, Balderston J, Receveur O, Lein D \& Hudes M (1992) Village Nutrition in Egypt, Kenya, and Mexico: Looking across the CRSP Projects. Final Report to USAID. Berkeley, CA: University of California.

Castillo-Duran C \& Uauy R (1988) Copper deficiency impairs growth of infants recovering from malnutrition. Am J Clin Nutr 47, $710-714$.

Chusilp K, Somnasang P, Kirdpon W, Wongkham S, Sribonlue P, Mahaverawat U, Yongvanit P, Sawakontha S \& Waterlow J (1992) Observations on the development of stunting in children of the Khon Kaen region of Thailand. Eur J Clin Nutr 46, $475-487$.

Clausen T \& Dorup I (1998) Micronutrients, minerals and growth control. Bibl Nutr Dieta 54, 84-92.

Dewey K, Beaton G, Fjeld C, Lonnerdal B \& Reeds P (1996) Protein requirements of infants and children. Eur J Clin Nutr 50, Suppl., S119-S150.

Frisancho AR (1981) New norms of upper limb fat and muscle areas for assessment of nutritional status. Am J Clin Nutr 34, 2540-2545.

Garn S, Rohmann C, Behar M, Viteri F \& Guzman M (1964) Compact bone deficiency in protein-calorie malnutrition. Science $\mathbf{1 4 5}$, $1444-1445$.

Gibson R (1990) Principles of Nutritional Assessment. New York: Oxford University Press.

Government of Kenya/United Nations Children's Fund (1998) Situation Analysis of Children and Women in Kenya 1998. Nairobi: Ministry of Planning and National Development, Human Resources and Social Services Department /UNICEF Kenya Country Office.

Graham G \& Adrianzen B (1972) Late 'catch-up' growth after severe infantile malnutrition. Johns Hopkins Med J 131, 204-211.

Graham GG, Creed HM, MacLean WC Jr, Kallman CH, Rabold J \& Mellits ED (1981) Determinants of growth among poor children: nutrient intake-achieved growth relationships. Am J Clin Nutr 34, 539-554.

Grillenberger M, Neumann CG, Murphy SP, Bwibo NO, van't Veer P, Hautvast JG \& West CE (2003) Food supplements have a positive impact on weight gain and the addition of animal source foods increases lean body mass of Kenyan schoolchildren. J Nutr 133, Suppl., S3957-S3964.

Hallberg L \& Hulthén L (2000) Prediction of dietary iron absorption: an algorithm for calculating absorption and bioavailability of dietary iron. Am J Clin Nutr 71, 1147-1160.

Institute of Medicine (1998) Dietary Reference Intakes for Thiamin, Riboflavin, Niacin, Vitamin $B_{6}$, Folate, Vitamin $B_{12}$, Pantothenic Acid, Biotin, and Choline. Washington, DC: National Academy Press.

Institute of Medicine (2001a) Dietary Reference Intakes for Vitamin A, Vitamin K, Arsenic, Boron, Chromium, Copper, Iodine, Iron, Manganese, Molybdenum, Nickel, Silicon, Vanadium and Zinc. Washington, DC: National Academy Press.

Institute of Medicine (2001b) Dietary Reference Intakes for Calcium, Phosphorus, Magnesium, Vitamin D, and Fluoride. Washington, DC: National Academy Press.

Judisch JM, Naiman JL \& Oski FA (1966) The fallacy of the fat irondeficient child. Pediatrics 37, 987-990.

Kulin HE, Bwibo N, Mutie D \& Santer SJ (1982) The effect of chronic childhood malnutrition on pubertal growth and development. Am J Clin Nutr 36, 527-536.

Marquis G, Habicht J, Lanata C, Black R \& Rasmussen K (1997) Breast milk or animal-product foods improve linear growth of Peruvian toddlers consuming marginal diets. Am J Clin Nutr 66, 1102-1109.

Mele L, West KP Jr, Kusdiono, Pandji A, Nendrawati H, Tilden RL \& Tarwotjo I (1991) Nutritional and household risk factors for xerophthalmia in Aceh, Indonesia: a case-control study. The Aceh Study Group. Am J Clin Nutr 53, 1460-1465.

Murphy SP, Calloway DH \& Beaton GH (1995) Schoolchildren have similar predicted prevalences of inadequate intakes as toddlers in village populations in Egypt, Kenya, and Mexico. Eur J Clin Nutr 49, 647-657

Murphy SP, Gewa C, Liang L-J, Grillenberger M, Bwibo NO \& Neumann CG (2003) School snacks containing animal source foods improve dietary quality for children in rural Kenya. $J$ Nutr 133, Suppl., S3950-S3956.

Neumann CG \& Bwibo NO (1987) Final Report: Food Intake and Human Function, Kenya Project. Washington, DC: Human Collaborative Support Program, United States Agency for International Development, Office of Nutrition.

Neumann CG, Bwibo NO, Murphy SP, Sigman M, Whaley S, Allen LH, Guthrie D, Weiss RE \& Demment MW (2003) Animal source foods improve dietary quality, micronutrient status, growth and cognitive function in Kenyan school children: background, study design and baseline findings. J Nutr 133, Suppl., S3941-S3949.

Paik H, Hwang S \& Lee S (1992) Comparative analysis of growth, diet, and urinary $\mathrm{N}$ excretion in elementary school children from urban and rural areas of Korea. Int J Vitam Nutr Res 62, 83-90.

Prentice A \& Bates CJ (1994) Adequacy of dietary mineral supply for human bone growth and mineralisation. Eur J Clin Nutr 48, Suppl., S161-S177.

Proos LA, Hofvander Y \& Tuvemo T (1991) Menarcheal age and growth pattern of Indian girls adopted in Sweden. II. Catch-up growth and final height. Indian J Pediatr 58, 105-114.

Rao K, Radhiah G \& Raju S (1980) Association of growth status and the prevalence of anemia in preschool children. Indian J Med Res 71, 237-246.

Santos L, Dricot J, Asciutti L \& Dricot-d'Ans C (1983) Xerophthalmia in the state of Paraiba, northeast of Brazil: clinical findings. Am J Clin Nutr 38, 139-144.

Sedgh G, Herrera M, Nestel P, el Amin A \& Fawzi W (2000) Dietary vitamin $\mathrm{A}$ intake and nondietary factors are associated with reversal of stunting in children. J Nutr 130, 2520-2526.

Siekmann JH, Allen LH, Bwibo NO, Demment MW, Murphy SP \& Neumann CG (2003) Kenyan school children have multiple 
micronutrient deficiencies, but increased plasma vitamin B-12 is the only detectable micronutrient response to meat or milk supplementation. J Nutr 133, Suppl., S3972-S3980.

Tanner J (1981) Catch-up growth in man. Br Med Bull 37, 233-238.

Tarwotjo I, Katz J, West KJ, Tielsch J \& Sommer A (1992) Xerophthalmia and growth in preschool Indonesian children. Am J Clin Nutr 55, 1142-1146.

Torun B, Davies PS, Livingstone MB, Paolisso M, Sackett R \& Spurr GB (1996) Energy requirements and dietary energy recommendations for children and adolescents 1 to 18 years old. Eur J Clin Nutr 50, Suppl., S37-S81.
Uauy R, Mize C \& Castillo-Duran C (2000) Fat intake during childhood: metabolic responses and effects on growth. Am J Clin Nutr 72, Suppl., S1354-S1360.

Walker SP, Powell CA \& Grantham-McGregor SM (1990) Dietary intakes and activity levels of stunted and non-stunted children in Kingston, Jamaica, Part 1. Dietary intakes. Eur J Clin Nutr 44, 527-534.

Whaley SE, Sigman M, Neumann C, Bwibo N, Guthrie D, Weiss RE, Alber S \& Murphy SP (2003) The impact of dietary intervention on the cognitive development of Kenyan school children. J Nutr 133, S3965-S3971. 